\title{
Effects of PTEN on the longevity of cultured human umbilical vein endothelial cells: The role of antioxidants
}

\author{
IZAK S. TAIT ${ }^{1}$, YAN LI $^{1-3}$ and JUN LU ${ }^{1-4}$ \\ ${ }^{1}$ School of Applied Sciences, Auckland University of Technology, Auckland 1010; ${ }^{2}$ School of Interprofessional Health Studies, \\ Auckland University of Technology, Auckland 0627; ${ }^{3}$ Institute for Applied Ecology New Zealand, \\ ${ }^{4}$ Institute of Biomedical Technology, Auckland University of Technology, Auckland 1010, New Zealand
}

Received September 13, 2014; Accepted November 3, 2014

DOI: 10.3892/ijmm.2014.1999

\begin{abstract}
Ageing is a major cause of illness, disease and mortality, mainly due to the shortening of telomeres, resulting in cells undergoing senescence and apoptosis. Increasing autophagy and the levels of antioxidants removes oxidants that cause DNA and telomere damage, thus reducing the rate at which telomeres shorten, resulting in a longer cellular lifespan. Phosphatase and tensin homolog (PTEN) has been shown to increase the lifespan of organisms by upregulating pathways involved in DNA damage repair, autophagy/antioxidants. The aim of this study was to investigate the effects of the overexpression of PTEN on the longevity of human cell cultures by examining the increase in antioxidant potential. Human umbilical vein endothelial cell (HUVEC) cultures were transfected with PTEN plasmids using lipofectamine. An assay was performed to quantify the protein levels of PTEN and the antioxidant potential of the cell cultures. The cell cultures were maintained until senescence occurred in order to determine longevity. The results of each assay were then compared and correlated with each other and with the longevity of the cells. The transfected cultures showed a significant increase in PTEN protein levels, total antioxidant potential and longevity (all P-values $<0.001$ ) compared with the non-transfected cell cultures. The correlation coefficient between cell longevity and PTEN levels was 0.8727 ; and the correlation coefficient between cell longevity and antioxidant potential was 0.6564 . The successful transfection of PTEN led to an increase in PTEN levels, antioxidant potential and an
\end{abstract}

Correspondence to: Dr Jun Lu, School of Applied Sciences, Auckland University of Technology, WS306, WS Building, City Campus, St. Paul Street, Auckland 1010, New Zealand

E-mail: jun.lu@aut.ac.nz

Abbreviations: AKT, protein kinase B; AOP-450, total antioxidant potential assay-450; ELISA, enzyme-linked immunosorbent assay; FoxO, forkhead protein O; HUVECs, human umbilical vein endothelial

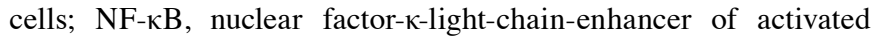
B cells; PI3K, phosphatidylinositol 3-kinase; PTEN, phosphotase and tensin homolog; ROS, reactive oxygen species

Key words: phosphatase and tensin homolog, antioxidant, ageing, longevity, human umbilical vein endothelial cells increased cellular longevity. This study demonstrates that there is a potential for PTEN to be used to extend human longevity. This can lay the foundation for further studies to be carried out on humans involving PTEN and longevity.

\section{Introduction}

Ageing may be described as 'an overall decline in the functional capacity of various organs to maintain baseline tissue homeostasis and to respond adequately to physiological needs under stress' (1). The symptoms of this decline are as many and varied as they are well documented, but are all ultimately linked to this functional inability to adequately respond to various stresses. These symptoms can range from sarcopenia (2), decreased musculoskeletal strength and mobility (3) to arthropathies and osteoporosis (4); from wrinkles to progressive normocytic anaemia (5); from a reduced immune response (6) to an impaired wound repair and stress response (7-10); from a reduction in liver and kidney function $(11,12)$ to a decreased heart rate and lung capacity (13); and most importantly, a deterioration of the brain's cognitive abilities afflicted by age-related diseases such as dementia, Alzheimer's disease and Parkinson's disease $(14,15)$.

One explanation for the ageing of tissues is the degradation of telomeres. While it has been demonstrated that telomeres alone do not cause ageing (16) and that other mechanisms play a role (17), telomeres have consistently been found to be key indicators of ageing $(18,19)$. The telomere hypothesis $(20)$ posits that telomere shortening can have an adverse effect on cellular ageing and this has been supported by a recent study that demonstrated that telomerase had the capacity to not only stop, but actively reverse tissue degeneration (21).

The major contributor to telomere shortening, beyond mitosis, is oxidative damage $(22,23)$ caused by metabolic processes and environmental elements. At a critically short length, telomeres cease to function as chromosome terminus caps and further shortening is then recognised by proteins, such as p53 and the cell undergoes senescence (24). Further DNA damage then results in apoptosis (25).

It has been hypothesised that this simple process is one of the major culprits in tissue and organ deterioration. This has been supported in studies on Dyskeratosis congenita (DC), a congenital disorder similar to progeria that resembles premature ageing (26). Patients with DC carry mutations in the 
telomerase RNA component and telomerase reverse transcriptase that results in poor protein stability, leading to increased telomere shortening (27).

Key casualties of telomere degradation are stem cells, the number of which declines with increasing age (1). This decline in the number of stem cells has been shown to result in tissue degeneration and atrophy (21), particularly in the muscular system (28), haematopoietic system (29) and nervous system (30). This decline is due to the deterioration of the regenerative ability of stem cells. The cause for this has been found to be, in the large part, the shortening of telomeres (31).

A critical feature of ageing that has been shown to have an impact on telomeres is autophagy, the ability of cells to catabolise unneeded, unwanted or dysfunctional elements within them. One such element is reactive oxygen species (ROS), which have been documented to cause DNA damage (32) and telomere shortening (23). Studies have demonstrated that increasing the rate of autophagy reduces the shortening of telomeres and can extend longevity (33-35); the reverse is also true: by inhibiting autophagy, the lifespan of an organism is reduced (36).

A method that could potentially increase the lifespan of humans would be through the increased effectiveness of autophagy, to prevent damage to DNA and to telomeres, thus reducing the impact of ageing and age-related complications. Phosphatase and tensin homolog (PTEN) has such a potential due to its reducing effects on DNA damage, its antioxidant activity, its role in caloric restriction, its suppressive effects on tumour replication, as reviewed in a previous study of ours [Tait et al (37)].

PTEN was first discovered in 1997 by two independent resesarch groups and was recognised as the long sought after tumour suppressor gene frequently lost on human chromosome 10q23 $(38,39)$. This locus is highly susceptible to mutation in human cancers: the frequency of mutations has been estimated to be $50-80 \%$ in sporadic tumours, such as glioblastomas, prostate cancers and endometrial carcinomas; and $30-50 \%$ in lung, colon and breast cancers. PTEN is often associated with advanced stages of cancer and metastases (40), due to the loss of PTEN having been observed at its highest frequency during the late stages of cancer. Together with p53, Ink4a and Arf, PTEN makes up the four most important tumour suppressors in mammals (41) as evidenced by their overall high frequency of inactivation across a variety of cancer types.

The gene that encodes PTEN is non-redundant and is expressed in the nucleus, cytoplasm and at the cellular membrane of all eukaryotic cells (42). The PTEN protein contains 403 amino acids and several domains (38). The crystal structure of PTEN shows a 179 residue $\mathrm{N}$-terminal domain and a 166 residue C-terminal domain (43). The $\mathrm{N}$-terminal domain contains a protein tyrosine phosphatase signature motif that is similar to dual specificity protein phosphatases. The $\mathrm{C}$-terminal domain contains the $\mathrm{C} 2$-domain that is responsible for its recruitment to phospholipid membranes.

The main function of PTEN is that of a phosphatidylinositol (3-5)-trisphosphate (PIP3) phosphatase to antagonise the phosphatidylinositol 3-kinase $(\mathrm{PI} 3 \mathrm{~K}) /$ protein kinase $\mathrm{B}$ (AKT) pathway by removing the D3 phosphate from the inositol ring, resulting in phosphatidylinositol 4,5-bisphosphate (PIP2) (44), thereby opposing the cell proliferative response of the pathway. While this has an impact on tumour formation, the importance to longevity is the downregulation of the forkhead protein $\mathrm{O}$ (FoxO) forkhead transcription factor by both AKT and nuclear factor- $\kappa$-light-chain-enhancer of activated B cells $(\mathrm{NF}-\kappa \mathrm{B})(45-47)$, inhibiting the antioxidant and stress resistance protein expression induced by FoxO $(48,49)$. The inhibition of the PI3K-AKT pathway may result in a higher level of antioxidants and increased autophagy, thus reducing the shortening of telomeres.

In concert with this function, PTEN has been reported to bind with the antioxidant gene, p53, to arrest the cell cycle whilst positively regulating proteins involved in DNA damage repair (50). These functions serve not only to extend cellular longevity, but also prevent to deleterious DNA damage that can lead to the development of malignant tumours (51). Higher levels of PTEN may result in lower levels of DNA damage caused by oxidation due to the effects of PTEN on autophagy, andmay also aid in the repair of any damage that may occur.

In this study, we used PTEN plasmids to treat human umbilical vein endothelial cell (HUVEC) cultures, verified by enzyme-linked immunosorbent assay (ELISA). We also measured the antioxidant potential, and analysed the correlations between antioxidant potential, cell longevity and PTEN expression, in order to ascertain whether increased levels of PTEN have a positive effect on the longevity of HUVEC cultures. Our results demonstrate that PTEN has positive effects on the longevity of animal tissues and organs; however, further studies are required to investigate these effects on humans. The data from the present study serve as a proof of concept of the ability of PTEN to extend longevity in human cells and, potentially, to extend the human lifespan.

\section{Materials and methods}

Procurement of materials. The PTEN plasmid was obtained from OriGene (Rockville, MD, USA) as a complete plasmid (Cat. no. RC202627). The PTEN ELISA kit was acquired from Antibodies-online.com (Atlanta, GA, USA). The reason for selecting an ELISA kit over a western blotting kit was that ELISA would deliver more quantifiable results that would be much better suited to be used in mathematical modelling than western blotting. The total antioxidant potential assay-450 (AOP-450) assay kit was obtained from OxisResearch, a division of Oxis Health Products (Portland, OR, USA). The HUVECs and the mediaum required for culture (Medium 200 and low serum growth supplement), were acquired from Life Technologies (Grand Island, NY, USA). The HUVECs were all from a single donor so as to ensure similarity of cellular physiology. As the supplier, Life Technologies covered any ethical concerns. Authentication and microbial inspections were performed by the supplier. Supplier protocols were followed.

Transfection of HUVEC cultures. The day prior to transfection, the cell cultures were trypsinised, and the cells were counted and replated at $8 \times 10^{4}$ cells/well in $1 \mathrm{ml}$ of complete medium 200 . DNA $(10 \mu \mathrm{g})$ was diluted into $100 \mu \mathrm{l}$ of distilled water and $10 \mu \mathrm{l}$ of this was removed for use in transfection. The remainder was frozen, for emergency purposes. The $10 \mu \mathrm{l}$ of diluted DNA was diluted into 6 aliquots of $0.1 \mu \mathrm{g}$ of DNA, 5 aliquots of $0.01 \mu \mathrm{g}$ of DNA and 1 aliquot of $1 \mu \mathrm{g}$ of DNA. The DNA was then added into 12 vials of $200 \mu \mathrm{l}$ Opti-MEM reduced serum medium. PLUS ${ }^{\mathrm{TM}}$ 
Reagent (Life Technologies) was added at a 1:1 ratio to the diluted DNA and incubated for 5-15 min at room temperature. For the 3 columns of the 12-well plate, Lipofectamine LTX was added at a ratio of 2:1, 3:1 and 5:1 to the DNA in each respective column. The vials were incubated for $25 \mathrm{~min}$ at room temperature. The growth medium was removed from the cells and replaced with Opti-MEM reduced serum medium. A total of $200 \mu \mathrm{l}$ of the DNA-Lipofectamine LTX complexes was added to each cell, making sure to mark the well to indicate the amount of DNA and Lipofectamine LTX in that well. The plate was then incubated at $37^{\circ} \mathrm{C}, 5 \% \mathrm{CO}_{2}$ in an incubator for $24 \mathrm{~h}$ before the Opti-MEM reduced serum medium were replaced with Medium 200.

\section{Protein level determination}

Sample preparation. Three 12-well plates were seeded with HUVECs. They were marked as the control, negative control and test group. The control cultures were not modified in any way to serve as a baseline. The negative control cultures had an empty plasmid vector added to eliminate the possible effects of the plasmid vector. The test cultures had the complete PTEN plasmid added. The cells were washed once with phosphatebuffered saline (PBS). PBS was then removed and cell lysis buffer was added and the cells were homogenised. The cells were then centrifuged for $10 \mathrm{~min}$ at $4^{\circ} \mathrm{C}$ and the supernatant was removed for use.

Assay procedure. For each well to be assayed, $100 \mu \mathrm{l}$ of sample diluent and $100 \mu \mathrm{l}$ of cell lysate were vortexed before $100 \mu \mathrm{l}$ of this diluted cell lysate were added to each well. The plate was then incubated for $2 \mathrm{~h}$ at $37^{\circ} \mathrm{C}$. The plate contents were removed and the wells were washed 4 times with $200 \mu$ l of wash buffer. A total of $100 \mu \mathrm{l}$ of detection antibody was added to each cell and the plate was incubated for $1 \mathrm{~h}$ at $37^{\circ} \mathrm{C}$ before being washed again. A total of $100 \mu \mathrm{l}$ of HRP-linked secondary antibody was added to each cell and the plate was again incubated for $30 \mathrm{~min}$ at $37^{\circ} \mathrm{C}$. The wells were washed again as described above. TMB substrate $(100 \mu \mathrm{l})$ was added to each well and the plate was incubated for $10 \mathrm{~min}$ at $37^{\circ} \mathrm{C}$. Stop solution $(100 \mu \mathrm{l})$ was added to each cell and the plate was agitated. The plate was read by a microplate reader at $450 \mathrm{~nm}$ to ascertain the results.

Statistical analysis. The cells in each well used were counted prior to performing the assay in order to display the data per $10 \times 10^{4}$ cells. The normalised results were then compared against the control samples, as well as each other using linear models and t-tests for analysis of significance.

\section{Determination of total antioxidant potential}

Sample preparation. The cells were washed 3 times with PBS prior to lysis. The cells were lysed by homogenization and then centrifuged at $3,000 \mathrm{xg}$ for $12 \mathrm{~min}$. The supernatant was removed and used for the assay.

Assay procedure. Both the samples and provided standards were diluted in dilution buffer at a ratio of 1:40 to create a $600 \mu 1$ solution. A total of $200 \mu 1$ of diluted samples or standards was pipetted into each well with pure dilution buffer used as reagent blanks. The plate was then read by a microplate reader at $450 \mathrm{~nm}$ for a reference measurement. Copper solution $(50 \mu \mathrm{l})$ was added to each well. The only incubation period for this experiment was for $3 \mathrm{~min}$ at room temperature. Stop solution $(50 \mu \mathrm{l})$ was then added and the plate was read for a second time at $450 \mathrm{~nm}$.
Statistical analysis. Readings taken before the copper and stop solutions were added was subtracted from the readings taken after the solutions were added. This equated to the net absorbance. A standard curve was created using the Trolox standards. The data were displayed in terms of $\mu \mathrm{M}$ Trolox equivalents and $\mu \mathrm{M}$ copper reducing equivalents (CREs) by dividing the samples by the slope, calculated from the standard curve, or expressed as follows: solve for $\mathrm{x}: y=m x$, where $y$ represents the assay readings and $m$ represents the slope.

The samples were then normalised per the cell numbers and compared, firstly, to the control samples and then with each other using t-tests.

Thawing of HUVEC cultures. The HUVECs were removed from liquid nitrogen storage and thawed in a $37^{\circ} \mathrm{C}$ water bath. The cells were moved to a class II, type A laminar flow culture hood and the contents were agitated to disperse the cells. A total of $20 \mu \mathrm{l}$ was removed and suspended in $20 \mu \mathrm{l}$ of trypan blue solution for cell counting. The vial contents were diluted, with Medium 200 with the addition of low serum growth supplement (LSGS), to a concentration of $1.24 \times 10^{4}$ and added to culture flasks. The flasks were incubated at $37^{\circ} \mathrm{C}$, with $5 \%$ $\mathrm{CO}_{2}$.

HUVEC culture maintenance. The culture medium was replaced with fresh complete medium 200, 24 h after establishing the culture from cryopreservation. For subsequent subcultures, the medium was replaced on a $48 \mathrm{~h}$ basis until the cultures were $80 \%$ confluent.

Passaging HUVEC cultures. The flasks were viewed under a Telaval 3 microscope (Carl Zeiss Technika Kft., Budaors, Hungary) to ascertain their condition, i.e., confluency, mitotic activity and signs of contamination. Flasks that were at least $80 \%$ were passaged. To subculture the $75 \mathrm{~cm}^{2}$ flasks, the culture medium as removed and TrypLE Express was added to each flask and incubated for 1-3 min. The flasks were agitated to ensure the cells had been dislodged from the surface. Complete Medium 200 was added to neutralise the effects of the TrypLE Express. This solution was agitated to remove any further cells and to break up cell clumps in the solution. The cells were then pipetted into centrifuge tubes and centrifuged at $180 \mathrm{x} \mathrm{g}$ for $7 \mathrm{~min}$. The supernatant was removed from the tube, with care being taken not to dislodge the cell pellet. The cell pellets were re-suspended in Medium 200 and reseeded into flasks. These were incubated at $37^{\circ} \mathrm{C}$, with $5 \% \mathrm{CO}_{2}$.

Evaluation of cell growth. Cell numbers were counted at each passage level and recorded. This was used to determine the number of cell divisions each culture underwent as a measure of their longevity. The number of cell divisions was ascertained by dividing the duration of the culture by the doubling time of the cells. The doubling time was established by using the following formula:

$$
\begin{gathered}
\mathrm{N} 1=\mathrm{N} 0^{*} 2 \mathrm{t} / \mathrm{T} \\
\mathrm{T}=\mathrm{t}^{*} \ln (2) /[\ln (\mathrm{N} 1)-\ln (\mathrm{N} 0)]
\end{gathered}
$$

where N0 represents the initial concentration of cells, N1 represents the final concentration of cells, $t$ represents the 
duration of culture, $\mathrm{T}$ represents the doubling time and $\mathrm{ln}$ represents the natural logarithm.

The total number of cell divisions in each well for each culture was compared using a t-test in order to determine whether there was a statistically significant difference between the samples.

To determine whether the total antioxidant potential and/or PTEN levels were responsible for any change in longevity, correlatory plots were created using the longevity against antioxidant potential and against PTEN levels, testing the significance of the slope. Pearson product-moment correlations were performed in order to measure the linear correlation between PTEN protein levels, antioxidant potential and cell longevity.

\section{Results}

Genetic overexpression of PTEN and protein level determination. PTEN plasmids were successfully transfected into 5 culture sets: a control set; a negative control set in which only an empty vector was transfected; and 3 doses of the PTEN plasmid: $0.1,0.01$ and $1 \mu \mathrm{g}$. Only one $1 \mu \mathrm{g}$ sample was included due to preliminary trials showing it to be too toxic for the HUVEC cultures. The success of the transfection was indicated by ELISA quantification of the PTEN protein levels.

Fig. 1 shows the mean absorbance (in grey) of the 5 groups normalised per cell number. There is a distinct grouping between those cells that have not been transfected and those that have. Amongst the individual data points, the lowest value is 0.0604 (negative control), while the highest value is 0.2093 (0.1 $\mu \mathrm{g}$ PTEN).

T-tests revealed that both 0.1 and $0.01 \mu \mathrm{g}$ sets showed a statistically significant increase over the control set (P-values of 0.0015 and 0.0019 , respectively) indicating that there was a clear increase in the production of PTEN protein in the transfected cultures. Further t-tests revealed no statistically significant differences between the 0.1 and $0.01 \mu \mathrm{g}$ sets (P-value $=0.2877)$. Combining the 0.1 and $0.01 \mu \mathrm{g}$ sets into one superset, a t-test revealed an unsurprising statistically significant difference between the set itself and the control set (P-value $=0.0008)$.

There was no statistically significant difference between the negative control and the positive control sets $(\mathrm{P}$-value $=0.3085)$, suggesting that the transfected empty had no overt effect on the cells. Testing all PTEN transfected cultures against all non-PTEN-transfected cultures revealed a marked difference $\left(\mathrm{P}\right.$-value $\left.=5.283 \times 10^{-8}\right)$ indicating a successful transfection. It was not possible to perform a t-test between the set itself and the control set, as the $1 \mu \mathrm{g}$ set only contained one sample.

During the preliminary trial of the transfection, only one dose (at $1 \mu \mathrm{g}$ was used) was used. Although manufacturer's instructions were followed, this resulted in total cell death of all transfected culture wells.

Due to the known ability of PTEN to cause senescence and apoptosis $(52,53)$, it may be possible that an overdose of the plasmid caused this and thus it was decided that in the subsequent transfection, 0.01 and $0.01 \mu \mathrm{g}$ doses of the PTEN plasmids would be used with only one well transfected with a $1 \mu \mathrm{g}$ dose to determine whether the cell death would occur again. The results demonstrated that it clearly did not. This, however, led to the issue that as the $1 \mu \mathrm{g}$ group only contained

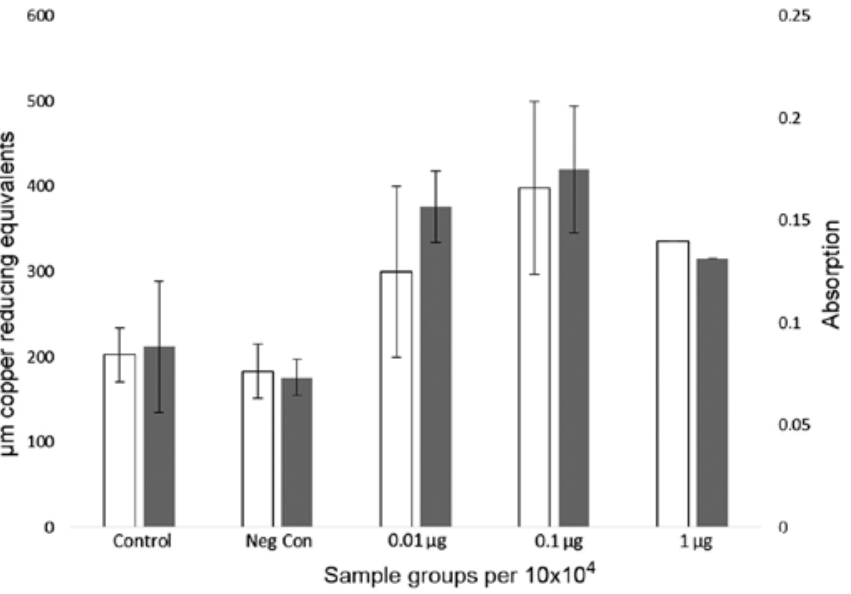

Figure 1. Mean absorbance of the 5 groups normalised per cell number. Grey bars indicate mean absorbance, with standard deviations above and below the mean of the 5 sets of samples, of phosphatase and tensin homolog (PTEN) protein levels normalised per $10 \times 10^{4}$ cells. White bars represent the mean $\mu \mathrm{M}$ copper reducing equivalents with standard deviations above and below the mean, normalised to $10 \times 10^{4}$ cells.

one sample, it was not possible to perform a t-test comparison between the group itselft and any other individual group.

Determination of total antioxidant potential. An AOP-450 assay was performed on all cultures to determine the total antioxidant potential in the cultures with the intent on determining whether the PTEN-transfected cultures produced a higher total antioxidant potential than the non-transfected cultures.

The data were normalised per cell number and were then expressed as $\mu \mathrm{M}$ CRE per $10 \times 10^{4}$ cells, as shown in Fig. 1. As with the above results, the minimum value is a part of the non-transfected cultures, while the maximum value is a part of the transfected cultures. The minimum is the negative control (183.0997 \pm 31.4$)$ and the maximum is the $0.1 \mu \mathrm{g}(398.1716 \pm 101.6)$. With a control value of $202.4562 \pm 31.9$, it is unsurprising that the t-test between the $0.1 \mu \mathrm{g}$ set and the control set resulted in a P-value of 0.0041 , indicating a marked statistical significance.

Dissimilar to the above results, a t-test performed between the $0.01 \mu \mathrm{g}$ set and the control set resulted in a statistically insignificant P-value of 0.0957 , showing that the difference between these two sets was not significant. This may potentially be due to the high degree of variance in the $0.01 \mu \mathrm{g}$ set. The t-tests performed between the 0.01 and $0.1 \mu \mathrm{g}$ sets, and the control and negative control sets revealed both groups to be statistically similar (P-values of 0.144 and 0.3142 , respectively). Combining all transfected samples into a set, and all control samples into another as done above, resulted in a statistically significant P-value of 0.0002089.

Wtih respect to the variance of each set, the 0.01 and $0.1 \mu \mathrm{g}$ sets showed a variance of 8084.8 and 8607.4 , respectively. The control and negative control sets were at an order of magnitude less at 846.8 and 821.1 , respectively. This marked difference between the transfected and non-transfected cells was shown again when these two sets were taken as a whole with a variance of 9888.9 for the transfected cells and 927.6 for the non-transfected cells.

With the data collected from both assays, it is possible to compare the two sets. Fig. 2 illustrates the correlation coeffi- 


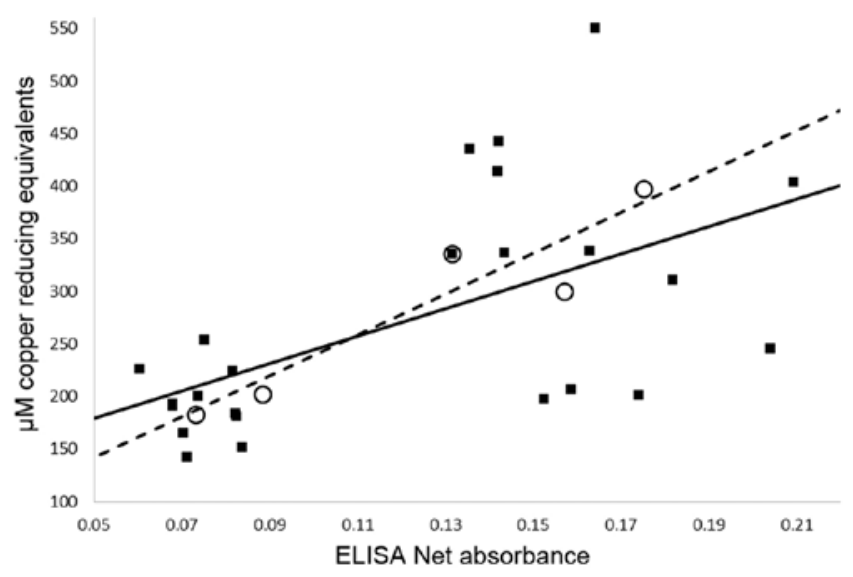

Figure 2. Scatter plot comparing the mean results (white circles, dotted regression slope) and individual results (black squares, solid regression slope) of phosphatase and tensin homolog (PTEN) protein expression and antioxidant potential. All values are normalised and displayed per $10 \times 10^{4}$ cells.

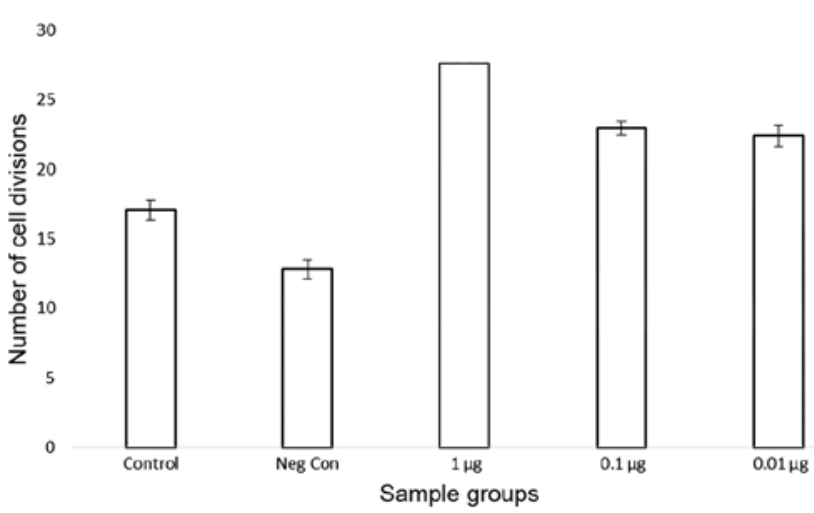

Figure 3. Mean number of cell divisions underwent by each sample culture with standard deviations above and below the mean.

cient scatter plot between the normalised results of the ELISA and AOP-450 assays. A visual positive correlation between the mean results was supported by a correlation coefficient of 0.936, suggesting an extremely close correlation between an increase in PTEN expression and an increase in the total antioxidant potential. However, when each data set was taken by their individual data points, also shown in Fig. 2, the Pearson product-moment correlation showed that the correlation coefficient was only 0.568 .

Evaluation of cell growth. The cell cultures were maintained and passaged until all the cells had died due to senescence and apoptosis to determine the effects of PTEN on the longevity of HUVEC cultures following transfection with PTEN. Fig. 3 shows the mean number of cell divisions each sample culture underwent. As with the above results, there was a marked difference between the transfected cultures and the nontransfected cultures.

Unlike the above results, t-tests revealed no significant difference betweenthe control and negative control cultures $\left(\mathrm{P}\right.$-value $\left.=9.04 \times 10^{-13}\right)$. The difference in values between the control culture and the $0.1 \mu \mathrm{g}\left(\mathrm{P}\right.$-value $\left.=1.25 \times 10^{-11}\right)$ and $0.01 \mu \mathrm{g}$ cultures $\left(\mathrm{P}\right.$-value $\left.=3.72 \times 10^{-6}\right)$ was significant. The difference between the 0.1 and $0.01 \mu \mathrm{g}$ cultures was found to be statistically

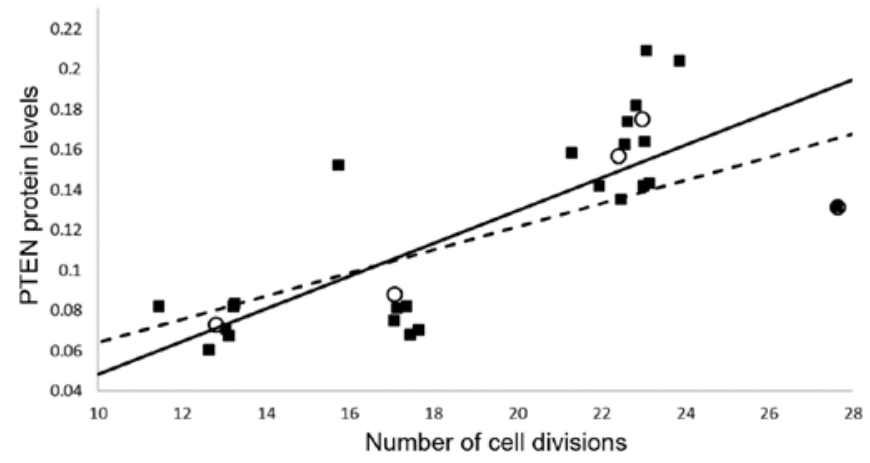

Figure 4. Scatter plot comparing the mean phosphatase and tensin homolog (PTEN) protein levels results (white circles, dotted regression slope) and individual protein levels (black squares, solid regression slope) and the number of cell divisions. All values are normalised and displayed per $10 \times 10^{4}$ cells.

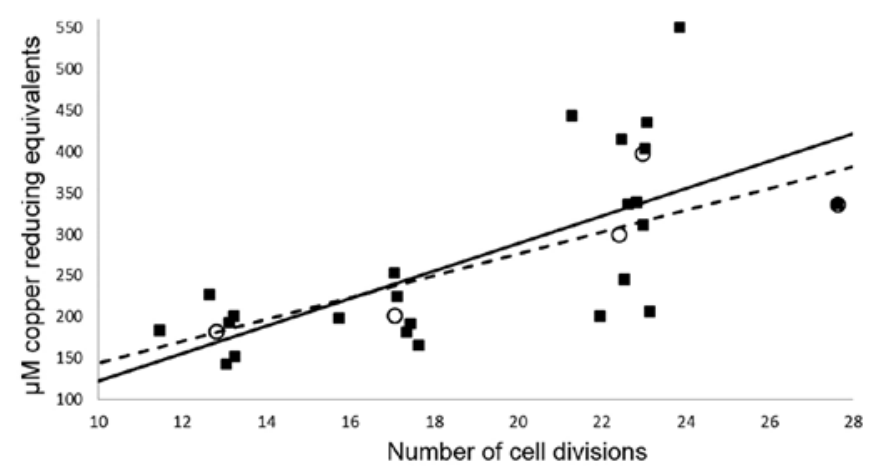

Figure 5. Scatter plot comparing the mean antioxidant potential (white circles, dotted slope) and the individual antioxidant potential (black squares, solid slope) and the number of cell divisions. All values are normalised and displayed per $\mu \mathrm{M}$ copper reducing equivalents per $10 \times 10^{4}$ cells.

insignificant $(\mathrm{P}$-value $=0.2035)$. The comparison of the transfected cells against the control yielded a P-value of $2.48 \times 10^{-9}$.

Fig. 4 shows the correlation between the total number of cell divisions and the PTEN protein levels. The Pearson product-moment correlation test between the mean values yieled a correlation coefficient of 0.7557 , suggesting a significant similarity between the two data sets.

With regard to the individual values shown in Fig. 4, the initial observations clearly showed two groupings of values, those from 11 to 18 on the horizontal axis, and those from 21 to 28 on the same axis. The former represent the nontransfected cells, while the latter the transfected cells. The correlation coefficient for these data resulted in a value of 0.7824 .

There are two observable outliers, one at 15.7356 and 0.1524 and the second at 27.6174 and 0.1314 . If one takes these two data points out of the set, one attains a correlation coefficient of 0.8727 .

A similar correlation graph between the CRE values and the number of cell divisions is shown in Fig. 5. A correlation coefficient of the mean values of 0.8376 showed an even closer correlation than ELISA vs. cell division.

Visually, there are 3 distinct groupings: from 11 to 14 , from 15 to 18 and from 21 to 24 on the horizontal axis. The first grouping is the negative control group, the second is the control group, while the third grouping is the transfected group. As 
with the results shown in Fig. 4, one can see the large degree of variance in the transfected group. This is supported by a correlation coefficient among the individual values of 0.6564 , suggesting only a moderate correlation between $\mu \mathrm{M}$ CRE and the number of cell divisions.

\section{Discussion}

The ultimate aim of this study was to examine the hypothesis that an increased level of PTEN, achieved by transfection, would increase the cellular longevity of HUVEC cultures. The purpose for this was to generate a proof of concept that may be applied in future studies, namely that PTEN may be beneficially used to increase human longevity.

As PTEN was first discovered as a cancer prevention gene, the majority of research has been spent in uncovering this aspect of PTEN. However, researchers have also examined the effects of PTEN on longevity independently of its anticancer properties $(41,54,55)$, revealing functions relating to longevity, such as protection from DNA damage (51), caloric restriction and protection from insulin resistance (41), as well as an increase in antioxidant levels $(48,56)$. It was on the basis of this research that this study attempted to apply these effects to human cells. The importance of a human trial is to demonstrate a proof of concept upon which further gerontological studies can be based. The importance of the study of longevity is not solely for the extension of human lifespan, but also for the extension of the human 'health span'.

Using the USA as a model for OECD nations, in 2009 it was speculated that the cost of age related health care was $6 \%$ of the GDP (57), and this accounted for $40 \%$ of all healthcare costs. This number is expected to increase in the coming years with the exponentially increasing ageing population (58). As regareds another of the characteristics of PTEN, that of caloric restriction, it is intriguing to note that the costs of obesity account for over 90 billion USD annually (59). These figures exclude the well documented worldwide costs of the treatment of cancer. The potential use of PTEN in humans as a preventative health measure then goes beyond the health of the individual and may potentially improve the health of society as a whole.

Apart from the important value that a successful transfection had to this study alone, the successful transfection of PTEN into a HUVEC culture is significant for further studies, as to the best of our knowledge, this study was the first to perform such a transfection. HUVECs have been used as a cellular model in the past, mainly for vascular studies (60), and these cells have been described as 'difficult to transfect using standard non-viral transfection methods' (61). Due to the possible applications that PTEN may have as a drug, this successful transfection then represents a major step forward for future studies involving the human transfection of PTEN.

With regard to ageing and longevity, PTEN's most prominent effect to potentially extending both is in its ability to positively regulate autophagy through its effects on the PI3K/ AKT pathway (62) and caloric restriction (41). It was for this reason that an antioxidant assay was used to determine whether an increase in PTEN levels would lead to an increase in the levels of antioxidants, and thus increased autophagy.

The principle behind the AOP-450 assay is the reduction of the levels of copper+2 $\left(\mathrm{Cu}^{2+}\right)$ to copper+1 $\left(\mathrm{Cu}^{+}\right)$. Copper, in its forms of $\mathrm{Cu}^{2+}$ and $\mathrm{Cu}^{+}$, is involved in a number of metabolic processes (63); however, its most pertinent ability is the capacity of $\mathrm{Cu}^{2+}$ to form ROS molecules and increase oxidative damage (64). By reducing $\mathrm{Cu}^{2+}$ to $\mathrm{Cu}^{+}$, it is effectively reducing the potential oxidative stress, and, logically, the higher the antioxidant potential, the more $\mathrm{Cu}^{2+}$ will be reduced to $\mathrm{Cu}^{+}$.

Fig. 1 shows the expected results from the AOP-450 assay, following normalisation, namely that an increase in PTEN levels does in fact increase the total antioxidant potential. However, the difference between the $0.01 \mu \mathrm{g}$ set and the control set was not statistically significant. This can be relegated to the large variance in the 0.01 and $0.1 \mu \mathrm{g}$ sets (and one can presume the $1 \mu \mathrm{g}$, had it had more samples), compared with the non-transfected sets. This sheds some doubt that PTEN can reliably increase a cell's antioxidant rate and may indicate that the processes involved in these pathways may not be uniformly affected by PTEN, thus showing greatly varying antioxidant levels.

In saying that, there was no significant difference observed between the two sets of transfected cultures, once again owing to the large degree of variance, and when the transfected groups as a whole were compared against the non-transfected groups, the resulting P-value was highly significant. This shows that despite the large degree of variance, PTEN does have an effect on antioxidant levels.

A way in which one can be more certain of this is by examing the results of the negative control set and its associated P-value when compared with the control set, which was highly insignificant. With the only differences between the control set and transfected sets being the differing levels of PTEN and a vector, once the vector is ruled out, one can say with a degree of certainty that this is due to the levels of PTEN.

The significance of this, beyond a statistical sense, is the effect of antioxidants on the longevity of cells. Oxidative damage can reduce a cell's longevity by damaging key parts of the DNA required for proper operation of the cell (65). By damaging these key areas, the cell stops proper operation and enters senescence and apoptosis. Another area prone to DNA damage are the telomeres, which, when reaching a critical stage will force the cell to enter senescence (31). By the reduction of oxidants, such as ROS and thus DNA damage, it is possible to increase cellular longevity.

Considering the noted capacity of PTEN to positively regulate genes and proteins involved in autophagy, such as FoxO (48), and its negative regulation of pathways resulting in oxidative damage $(46,66)$, if an increased level of PTEN leads to an increased antioxidant potential (which the AOP-450 assay results suggested) then it is quite possible to speculate that a possible route to enhancing longevity is by increasing the levels of PTEN.

While the AOP-540 assay revealed that increased levels of PTEN resulted in an increased antioxidant potential, there was a high degree of variance and overlap between the data of the separate sets, casting doubt upon the reliability of these results. However, there is a plausible biological explanation for the high degree of variance.

The main effect PTEN has on antioxidant levels while in the cytoplasm is to downregulate the PI3K/AKT pathway $(67,68)$. By downregulating PIP3, downstream effectors of the PI3K/AKT pathway, such as NF- $\kappa \mathrm{B}$ have a reduced capacity to downregulate FoxO (45-47). This in turn allows 
FoxO to greatly induce the expression of several antioxidant enzymes (48). Conversely, the effect of PTEN on antioxidants in the nucleus derives from its interaction with the p53 protein. By binding with p53, PTEN is able to enhance p53-mediated functions (69), among which is the increased production of the p53 downstream antioxidant gene, sestrin (56).

While there are many mechanisms through which PTEN may travel between the cytoplasm and the nucleus, such as by diffusion, active shuttling and pathway-dependent exportation $(70,71)$, one mechanism of note is the promotion of nuclear PTEN as a result of apoptotic stimuli (52), where it enhances these apoptotic stimuli. This can be seen as another process of PTEN where it is in direct confrontation with the PI3K/AKT pathway, which opposes apoptosis (72) as one of its mechanisms to promote survival and proliferation. A speculation on the purpose behind PTEN's enhancement of apoptotic stimuli is the destruction of cells containing potential toxic material, thus keeping the overall health of tissues at an optimal level.

The link between this and the variance observed in the 0.01 and $0.1 \mu \mathrm{g}$ results (Fig. 1) and the low correlation coefficients in Fig. 2 may be one of timing. The AOP-450 assay was performed during the 9th passage of culture. This is near the end of the passaging lifespan of HUVEC cultures, and as such the proportion of cells entering apoptosis would have been higher than in earlier cultures. The apoptotic stimuli in these cells would have resulted in a greater nuclear import of PTEN than normal, leading to a higher proportion of antioxidants mediated by $\mathrm{p} 53$ than by FoxO.

As these two pathways operate by different means, their differing proportions may have been responsible for this great variance. With two independent pathways, the mechanisms by which they affect antioxidant levels would also differ. As such, this may lead to different cultures having greatly differing results, depending on the proportion of PTEN nuclear import in each culture. The antioxidant properties of FoxO and p53 in relation to PTEN import in response to apoptotic stimuli would be a fascinating avenue for future research.

PTEN may have positively influenced the longevity of the transfected HUVEC cultures through the indirect maintenance of DNA damage and telomeres through Rad51, as well as through the increase in antioxidant levels.

It would be of great research interest to investigate further how different doses of PTEN may affect cell cultures. This would be of great interest when dealing with the two extremes of doses: to determine the highest dose of PTEN that could be used without destroying the cultures, and the lowest dose that could be used while still showing a statistically significant difference.

In a similar vein, the use of other cell lines in respect to PTEN transfection would also prove interesting. HUVECs have been used as a cell model in a number previous studies, although this has been mostly for endothelial or vascular research (73-75). Using other cell lines would prove beneficial towards determining whether the observed effects of PTEN in this study may be replicated in other cells. The importance of this clearly would be to provide further groundwork for any future human trials, particularly if deleterious effects were to be found.

As regards PTEN transfection, it would be of great interest to examine the combined transfection of PTEN and telomerase reverse transcriptase (hTERT) in mice to determine whether the combined effects of these two genes are more than the sum of their parts. PTEN transfection and overexpression in mice have been shown to increase longevity and metabolism, and protect the organism from both insulin resistance and cancer (41). The overexpression hTERT leads to telomerase reactivation, which was found to reverse tissue degeneration in artificially aged mice (21). Perhaps PTEN may offset the capacity of telomerase to induce the formation of tumours.

\section{Acknowledgements}

The authors would like to thank the School of Applied Sciences and the Faculty of Health and Environmental Sciences, Auckland University of Technology, New Zealand for the financial support of this study.

\section{References}

1. Sahin E and Depinho RA: Linking functional decline of telomeres, mitochondria and stem cells during ageing. Nature 464: 520-528, 2010.

2. Thomas DR: Sarcopenia. Clin Geriatr Med 26: 331-346, 2010.

3. Leveille SG: Musculoskeletal aging. Curr Opin Rheumatol 16: 114-118, 2004.

4. Tung S and Iqbal J: Evolution, aging, and osteoporosis. Ann NY Acad Sci 1116: 499-506, 2007.

5. Balducci L: Anemia, fatigue and aging. Transfus Clin Biol 17: 375-381, 2010.

6. Goronzy JJ and Weyand CM: Immune aging and autoimmunity. Cell Mol Life Sci 69: 1615-1623, 2012.

7. Raekallio J: The effect of ageing on enzymes in wound healing. A histochemical and biochemical study. Geron 21: 31-35, 1977.

8. Emmerson E and Hardman MJ: The role of estrogen deficiency in skin ageing and wound healing. Biogerontology 13: 3-20, 2012.

9. Ashcroft GS, Mills SJ and Ashworth JJ: Ageing and wound healing. Biogerontology 3: 337-345, 2002.

10. Ashcroft GS, Horan MA and Ferguson MW: The effects of ageing on cutaneous wound healing in mammals. J Anat 187: 1-26, 1995.

11. Grizzi F, Di Caro G, Laghi L, et al: Mast cells and the liver aging process. Immun Ageing 10: 9, 2013.

12. Schmitt R and Melk A: New insights on molecular mechanisms of renal aging. Am J Transplant 12: 2892-2900, 2012.

13. Knight $J$ and Nigam Y: Exploring the anatomy and physiology of ageing. Part 1 - The cardiovascular system. Nurs Times 104: 26-27, 2008.

14. Hung CW, Chen YC, Hsieh WL, Chiou SH and Kao CL: Ageing and neurodegenerative diseases. Ageing Res Rev 9 (Suppl 1): S36-S46, 2010

15. Carroll B, Hewitt G and Korolchuk VI: Autophagy and ageing: implications for age-related neurodegenerative diseases. Essays Biochem 55: 119-131, 2013.

16. Kipling D and Faragher RG: Telomeres. Ageing hard or hardly ageing? Nature 398: 191, 193, 1999.

17. Kenyon CJ: The genetics of ageing. Nature 464: 504-512, 2010.

18. Jiang $\mathrm{H}, \mathrm{Ju} \mathrm{Z}$ and Rudolph KL: Telomere shortening and ageing. Z Gerontol Geriatr 40: 314-324, 2007.

19. Sahin E and DePinho RA: Axis of ageing: telomeres, p53 and mitochondria. Nat Rev Mol Cell Biol 13: 397-404, 2012.

20. Harley CB, Vaziri H, Counter CM and Allsopp RC: The telomere hypothesis of cellular aging. Exp Gerontol 27: 375-382, 1992.

21. Jaskelioff M, Muller FL, Paik JH, et al: Telomerase reactivation reverses tissue degeneration in aged telomerase-deficient mice. Nature 469: 102-106, 2011.

22. Chan SR and Blackburn EH: Telomeres and telomerase. Philos Trans R Soc Lond B Biol Sci 359: 109-121, 2004.

23. von Zglinicki T: Oxidative stress shortens telomeres. Trends Biochem Sci 27: 339-344, 2002.

24. Herbig U, Jobling WA, Chen BP, Chen DJ and Sedivy JM: Telomere shortening triggers senescence of human cells through a pathway involving ATM, p53, and p21(CIP1), but not p16(INK4a). Mol Cell 14: 501-513, 2004.

25. Mondello C and Scovassi AI: Telomeres, telomerase, and apoptosis. Biochem Cell Biol 82: 498-507, 2004.

26. Blasco MA: Telomeres and human disease: ageing, cancer and beyond. Nat Rev Genet 6: 611-622, 2005. 
27. Nelson ND and Bertuch AA: Dyskeratosis congenita as a disorder of telomere maintenance. Mutat Res 730: 43-51, 2012.

28. Cerletti M, Shadrach JL, Jurga S, Sherwood R and Wagers AJ: Regulation and function of skeletal muscle stem cells. Cold Spring Harb Symp Quant Biol 73: 317-322, 2008.

29. Linton PJ and Dorshkind K: Age-related changes in lymphocyte development and function. Nat Immunol 5: 133-139, 2004.

30. Maslov AY, Barone TA, Plunkett RJ and Pruitt SC: Neural stem cell detection, characterization, and age-related changes in the subventricular zone of mice. J Neurosci 24: 1726-1733, 2004.

31. Blasco MA: Telomere length, stem cells and aging. Nat Chem Biol 3: 640-649, 2007.

32. Wang Y: Bulky DNA lesions induced by reactive oxygen species. Chem Res Toxicol 21: 276-281, 2008

33. Rubinsztein DC, Mariño G, and Kroemer G: Autophagy and aging. Cell 146: 682-695, 2011.

34. Harris H and Rubinsztein DC: Control of autophagy as a therapy for neurodegenerative disease. Nat Rev Neurol 8: 108-117, 2012.

35. Fleming A, Noda T, Yoshimori T and Rubinsztein DC: Chemical modulators of autophagy as biological probes and potential therapeutics. Nat Chem Biol 7: 9-17, 2011.

36. Lee JH, Budanov AV, Park EJ, et al: Sestrin as a feedback inhibitor of TOR that prevents age-related pathologies. Science 327: $1223-1228,2010$

37. Tait IS, Li Y and Lu J: PTEN, longevity and age-related diseases. Biomedicines 1: 17-48, 2013.

38. Li J, Yen C, Liaw D, et al: PTEN, a putative protein tyrosine phosphatase gene mutated in human brain, breast, and prostate cancer. Science 275: 1943-1947, 1997.

39. Steck PA, Pershouse MA, Jasser SA, et al: Identification of a candidate tumour suppressor gene, MMAC1, at chromosome $10 \mathrm{q} 23.3$ that is mutated in multiple advanced cancers. Nat Genet 15: $356-362,1997$

40. Ali IU, Schriml LM and Dean M: Mutational spectra of PTEN/MMAC1 gene: a tumor suppressor with lipid phosphatase activity. J Natl Cancer Inst 91: 1922-1932, 1999.

41. Ortega-Molina A, Efeyan A, Lopez-Guadamillas E, et al: Pten positively regulates brown adipose function, energy expenditure, and longevity. Cell Metab 15: 382-394, 2012.

42. Sulis ML and Parsons R: PTEN: from pathology to biology. Trends Cell Biol 13: 478-483, 2003.

43. Lee JO, Yang H, Georgescu MM, et al: Crystal structure of the PTEN tumor suppressor: implications for its phosphoinositide phosphatase activity and membrane association. Cell 99: 323-334, 1999.

44. Maehama T and Dixon JE: The tumor suppressor,PTEN/MMAC1, dephosphorylates the lipid second messenger, phosphatidylinositol 3,4,5-trisphosphate. J Biol Chem 273: 13375-13378, 1998.

45. Adler AS, Sinha S, Kawahara TL, Zhang JY, Segal E and Chang HY: Motif module map reveals enforcement of aging by continual NF-kappaB activity. Genes Dev 21: 3244-3257, 2007.

46. Salminen A and Kaarniranta K: NF-kappaB signaling in the aging process. J Clin Immunol 29: 397-405, 2009.

47. Salminen A, Ojala J, Huuskonen J, Kauppinen A, Suuronen T and Kaarniranta $\mathrm{K}$ : Interaction of aging-associated signaling cascades: inhibition of NF-kappaB signaling by longevity factors FoxOs and SIRT1. Cell Mol Life Sci 65: 1049-1058, 2008.

48. Calnan DR and Brunet A: The FoxO code. Oncogene 27: $2276-$ 2288,2008

49. van der Horst A and Burgering BM: Stressing the role of FoxO proteins in lifespan and disease. Nat Rev Mol Cell Biol 8 : 440-450, 2007

50. Chang CJ, Mulholland DJ, Valamehr B, Mosessian S, Sellers WR and Wu H: PTEN nuclear localization is regulated by oxidative stress and mediates p53-dependent tumor suppression. Mol Cell Biol 28: 3281-3289, 2008.

51. Ming M, Feng L, Shea CR, et al: PTEN positively regulates UVB-induced DNA damage repair. Cancer Res 71: 5287-5295, 2011.
52. Gil A, Andres-Pons A, Fernández E, et al: Nuclear localization of PTEN by a Ran-dependent mechanism enhances apoptosis: Involvement of an N-terminal nuclear localization domain and multiple nuclear exclusion motifs. Mol Biol Cell 17: 4002-4013, 2006.

53. Wan X, Li J, Xie X and Lu W: PTEN augments doxorubicininduced apoptosis in PTEN-null Ishikawa cells. Int J Gynecol Cancer 17: 808-812, 2007.

54. Ming M and He YY: PTEN in DNA damage repair. Cancer Lett 319: 125-129, 2012.

55. Masse I, Molin L, Billaud M and Solari F: Lifespan and dauer regulation by tissue-specific activities of Caenorhabditis elegans DAF-18. Dev Biol 286: 91-101, 2005.

56. Wempe F, De-Zolt S, Koli K, et al: Inactivation of sestrin 2 induces TGF-beta signaling and partially rescues pulmonary emphysema in a mouse model of COPD. Dis Model Mech 3: 246-253, 2010

57. Hosseini H: Do health care professionals find the use of age-based rationing to reduce health care costs ethical? Humanomics 27: 282-299, 2011.

58. Christensen K, Doblhammer G, Rau R and Vaupel JW: Ageing populations: the challenges ahead. Lancet 374: 1196-1208, 2009.

59. Daviglus ML: Health care costs in old age are related to overweight and obesity earlier in life. Health Aff (Millwood) 24 (Suppl 2): W5R97-W5R100, 2005.

60. Rhim JS, Tsai WP, Chen ZQ, et al: A human vascular endothelial cell model to study angiogenesis and tumorigenesis. Carcinogenesis 19: 673-681, 1998

61. Lim J, Dobson J: Improved transfection of HUVEC and MEF cells using DNA complexes with magnetic nanoparticles in an oscillating field. J Genet 91: 223-227, 2012.

62. Ashcroft M, Ludwig RL, Woods DB, et al: Phosphorylation of HDM2 by Akt. Oncogene 21: 1955-1962, 2002.

63. Garcia L, Welchen E and Gonzalez DH: Mitochondria and copper homeostasis in plants. Mitochondrion: pii: S1567-7249(14)00025-7, 2014. doi: 10.1016/j.mito.2014.02.011.

64. Gaetke LM and Chow CK: Copper toxicity, oxidative stress, and antioxidant nutrients. Toxicology 189: 147-163, 2003.

65. Friedberg EC: DNA damage and repair. Nature 421: 436-440, 2003.

66. Carracedo A and Pandolfi PP: The PTEN-PI3K pathway: of feedbacks and cross-talks. Oncogene 27: 5527-5541, 2008.

67. Chalhoub $\mathrm{N}$ and Baker SJ: PTEN and the PI3-kinase pathway in cancer. Annu Rev Pathol 4: 127-150, 2009.

68. Stambolic V, Suzuki A, de la Pompa JL, et al: Negative regulation of PKB/Akt-dependent cell survival by the tumor suppressor PTEN. Cell 95: 29-39, 1998.

69. Chen Z, Trotman LC, Shaffer D, et al: Crucial role of p53-dependent cellular senescence in suppression of Ptendeficient tumorigenesis. Nature 436: 725-730, 2005.

70. Planchon SM, Waite KA and Eng C: The nuclear affairs of PTEN. J Cell Sci 121: 249-253, 2008.

71. Liu JL, Mao Z, LaFortune TA, et al: Cell cycle-dependent nuclear export of phosphatase and tensin homologue tumor suppressor is regulated by the phosphoinositide-3-kinase signaling cascade. Cancer Res 67: 11054-11063, 2007.

72. Datta SR, Dudek H, Tao X, et al: Akt phosphorylation of BAD couples survival signals to the cell-intrinsic death machinery. Cell 91: 231-241, 1997.

73. Geerts WJ, Vocking K, Schoonen N, et al: Cobblestone HUVECs: a human model system for studying primary ciliogenesis. J Struct Biol 176: 350-359, 2011.

74. Alex D, Lam IK, Lin Z and Lee SM: Indirubin shows antiangiogenic activity in an in vivo zebrafish model and an in vitro HUVEC model. J Ethnopharmacol 131: 242-247, 2010.

75. Campolo J, Vozzi F, Penco S, et al: Vascular injury post stent implantation: different gene expression modulation in human umbilical vein endothelial cells (HUVECs) model. PLoS One 9: e90213, 2014. 